\title{
Islak ve Kuru Ortamlarda Kullanılan Zemin Kaplamalarının Güvenlik Katsayılarının K-Ortalamalar ve Karar Ağacı Yöntemleriyle Değerlendirilmesi
}

\section{Evaluation of the Safety Coefficients of Floor Coverings Used in Wet and Dry Environments by K-Means and Decision Tree Methods}

\author{
Fatih Karataş $^{1 *}$, Ali Sarışık ${ }^{2}$, Gültekin Coşkun ${ }^{3}$ \\ ${ }^{1}$ Harran Üniversitesi, İnşaat Mühendisliği Bölümü, Şanlıurfa 205179006@ogrenci.harran.edu.tr \\ ORCID: https://orcid.org/0000-0002-8328-8550 \\ ${ }^{2}$ Harran Üniversitesi, İnşaat Mühendisliği Bölümü, Şanlıurfa sariisik@ harran.edu.tr \\ ORCID: https://orcid.org/0000-0001-7698-6134 \\ ${ }^{3}$ Cumhuriyet Üniversitesi, İş Sağlığı ve Güvenliği Programı, Sivas cgultekin@ @umhuriyet.edu.tr \\ ORCID: https://orcid.org/0000-0002-4182-2372
}

\begin{tabular}{|c|c|}
\hline MAKALE BİLGİLERİ & ÖZ \\
\hline \multicolumn{2}{|l|}{ Makale Geçmişi: } \\
\hline $\begin{array}{l}\text { Geliş } 13 \text { Ekim } 2021 \\
\text { Revizyon } 6 \text { Aralık } 2021 \\
\text { Kabul } 29 \text { Aralık } 2021 \\
\text { Online } 31 \text { Aralı } 2021\end{array}$ & $\begin{array}{l}\text { Topluma açık ve kapalı alanlarda insanların rahat hareket edebilmeleri için zemin kaplamalarının kaymaz } \\
\text { özellikte olması istenmektedir. Bu çalışma kapsamında } 7 \text { farklı kamu kurumunda } 5 \text { farklı alanda (Giriş, } \\
\text { Koridor, Oda, Merdiven, Lavabo) zemin kaplamalarının kuru ve islak ortam dinamik sürtünme katsayıları } \\
\text { DCOF ( } \mu \text { ) GMG } 200 \text { test cihazı kullanılarak DIN } 51131: 2014-03 \text {, EN } 13893 \text { ile TS CEN/TS } 16165 \text { Ek- D } \\
\text { standartlarına göre ölcülmüstür. Aritmetik ortalama ile elde edilen dinamik sürtünme katsavısı DCOF (u) }\end{array}$ \\
\hline Anahtar Kelimeler: & $\begin{array}{l}\text { değerleri RapidMINER programında K-Ortalamalar Yöntemi kullanılarak gruplanmış, oluşan küme } \\
\text { grupları sınır değerleri Karar Ağacı Yöntemi kullanılarak belirlenmiştir. Sonuçlar günümüzde Alman Kaza }\end{array}$ \\
\hline Zemin kaplamaları, Kayma direnci & Sigortası Sisteminde kullanılan ve güncel DIN 51131:2014- 03, EN 13893 ve TS CEN/TS 16165 Ek- D \\
\hline $\begin{array}{l}\text { K- Ortalamalar Yöntemi, Karar } \\
\text { Ağact Yöntemi }\end{array}$ & $\begin{array}{l}\text { Standartlarında geçen Wuppertaler Tabelası kullanılarak değerlendirilmiştir. Değerlendirme sonucu kamu } \\
\text { kurumlarına ait kaymazlık risk haritası çıkarılmış olup, en güvenli kurum K5 SGK kurumu olurken en } \\
\text { güvensiz kurum ise K3 Ana okulu olarak belirlenmiştir. } 7 \text { farklı kamu kurumunda da zemin kaplaması } \\
\text { olarak kullanılan seramik zemin kaplamalarının sürtünme katsayılarının düşük olduğu tespit edilmiş ve bu } \\
\text { zemin kaplamalarının dinamik sürtünme katsayısı yüksek malzemelerle değiştirilmesi veya gerekli } \\
\text { önleyici ve koruyucu tedbirlerin alınması önerilmiştir. }\end{array}$ \\
\hline
\end{tabular}

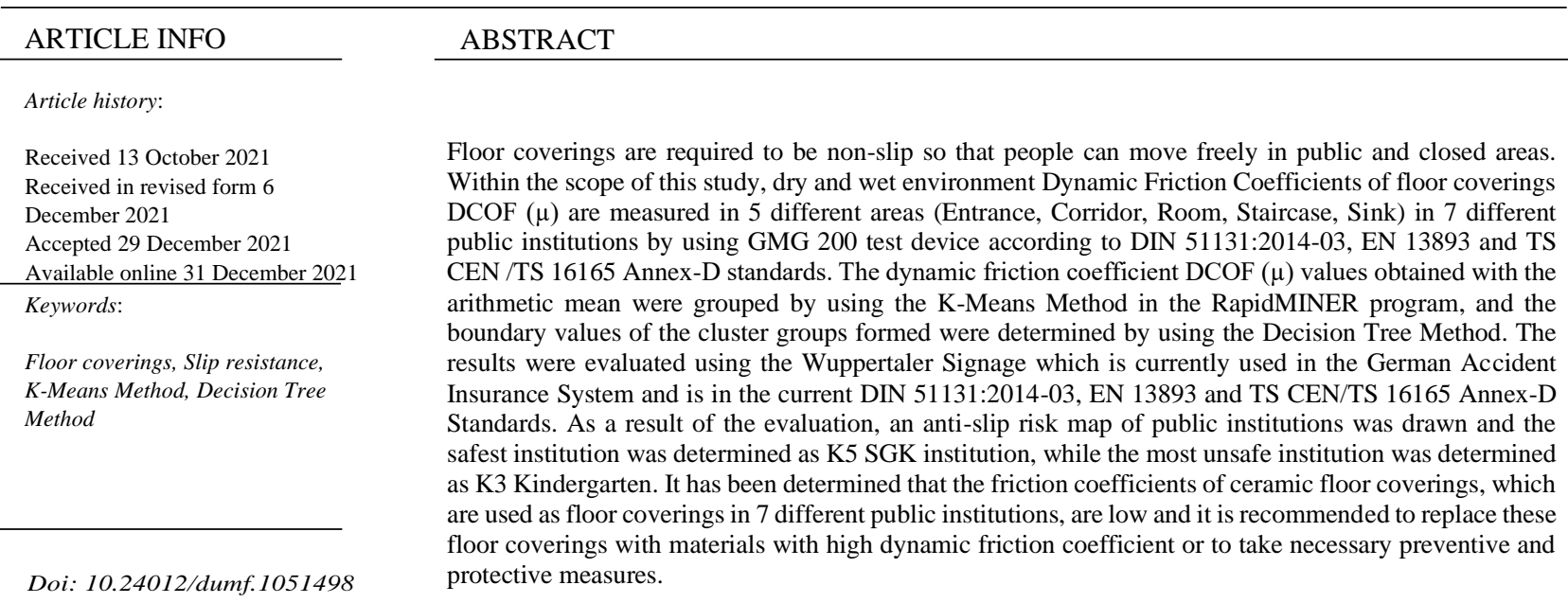




\section{Giriş}

İnşaat sektöründe farklı ortamlar için farklı türde ve özellikte çeşitli zemin kaplamaları kullanılmaktadır. Özellikle insanların sıklıkla hareket halinde bulundukları alanların zemin kaplamalarının kaydırmaz özellikte olması gerekmektedir. $\mathrm{Bu}$ zeminler üzerinde meydana gelebilecek kayma ve düşme kazalarının önlenebilmesi için tasarım öncesi zemin kaplaması olarak kullanılacak malzemelerin kayma risklerinin belirlenmesi son derece önemlidir.

Dünya çapında yapılan araştırma istatistiklerine göre kayma ve düşmeler nedeniyle meydana gelen yaralanma vakaları trafik kazaları sonucu meydana gelen yaralanma vakalarının ardından ikinci sırada yer almaktadır. Meydana gelen her 5 kazadan biri kayma ve düşme sonucu meydana gelmektedir. Amerika'daki kayma ve düşme vakaları incelendiğinde yılda ortalama 9 milyon vaka meydana gelirken, günlük 25.000 kişi kayma ve düşme vakaları nedeniyle yaralanmakta, 55 kişi hayatını kaybetmektedir. Yaralanma vakalarının \%55'i 40 yaşın üstündeki insanlarda, \%35'i çocuklarda görülmektedir. İş dünyasında kayma ve düşme vakaları sonucu meydana gelen maddi kaybın dünya ekonomisindeki payı 110 Milyar Euro iken ülkemizde bu kayıp yılda 554 Milyon Euro'dur [1].

SGK 2017 verilerine göre 2010 yılında 5510 sayılı kanunun 4-1/a maddesi kapsamında aktif sigortası bulunan çalışanların yaşadığı 62.903 iş kazasının 8992'sini kayma ve düşme vakaları oluşturmaktadır [2].

Resmi Gazete 'de 07 Temmuz 2015 tarihinde yayımlanarak yürürlüğe giren 5378 sayılı Engelliler Hakkında Kanun ve son yıllarda çıkarılan yasa ve yönetmeliklerle birlikte zemin kaplamalarında kullanılacak malzemelerinin kuru, sslak ve eğimli ortamlarda kaymaz özellikte olması istenmektedir. Ayrıca, üreticilerin son kullanıcıya ürünlerinin kaymaz özelliklerini gösteren işaret veya sınıflamaları bildirmeleri zorunlu kılınmıştır. Bu nedenle inşaat ve mimari projelerde kamu kurum ve kuruluşları başta olmak üzere özel sektör ve belediyelerin bu mevzuata uyması zorunlu hale getirilmiştir [3], [4].

Mevzuata aykırı yapılan zemin kaplama tasarımları sonrası meydana gelen kayma ve düşme vakaları sonucunda oluşan kazalarda davalar açılmakta ve yüksek miktarlarda tazminatlar ödenmektedir.

2010 y1lında bir mağazada düşerek yaralanan bir kişinin tüketici mahkemesine açtığ 1 dava sonucu işyeri toplamda 8 bin 275 TL tazminat ödemek durumunda kalmıştır [5].

2017 yılında İzmir'de çalıştığı hastanede 1slak zeminde düşen sağlık çalışanı çalıştığı ortamın güvenli olmadığı gerekçesiyle açtı̆̆ı davayı kazanarak tazminat almaya hak kazanmıştır [6].

2019 yılında İzmir'de gezmeye gittiği alışveriş merkezinde sslak zemin nedeniyle kayıp düşen spor eğitmeninin yaralanması nedeniyle açtığı dava sonucu 12 bin $275 \mathrm{TL}$ tazminat kazanmıştır [7].

Yeni çıkan kanun ve yönetmeliklere göre tüm özel ve Kamu kurumlarında kullanılan zemin kaplamalarında meydana gelen kayma ve düşme vakalarından hukuken yöneticiler sorumludur. Tüm Özel ve Kamu kurumlarında zemin kaplaması olarak kullanılan malzemelerin, kullanıldıkları alanlarda ıslak ve kuru ortamlar için kayma riskinin belirlenerek güvenlik sinıflandırmasının yapılması kaymazlık risk haritasının çıkarılması gerekmektedir. Bu tarz binalar inşa edilirken zeminlerde kullanılacak malzemelerin 1slak ve kuru ortamlar için standart ve yönetmeliklere uygun kaydırmaz özellikte seçilmesi ve bunun için yetkililerin bilgilendirilmesi gerekir [8], [9].

Bu çalışmada, seçilen 7 farklı kamu kurumundaki 5 farklı alan için GMG 200 test cihazı kullanılarak DIN 51131:201403, EN 13893 ile TS CEN/TS 16165 Ek - D standartlarına göre 1slak ve kuru ortam dinamik sürtünme katsayısı DCOF ( $\mu$ ) değerleri ölçülmüştür. Islak ve kuru her iki ortam için ölçüm değerlerinin aritmetik ortalaması RapidMiner programında K-Ortalamalar Yöntemi kullanılarak gruplanmış, oluşan küme grupları sınır değerleri Karar A ğacı Yöntemi kullanılarak belirlenmiştir. Sonuçlar günümüzde Alman Kaza Sigortası Sisteminde kullanılan ve güncel DIN 51131:2014- 03, EN 13893 ve TS CEN/TS 16165 Ek - D standartlarında geçen Wuppertaler Tabelası kullanılarak değerlendirilmiştir.

\section{Materyal ve Metot}

Topluma açık ve kapalı alanlarda, kamuya ait binalarda zemin kaplaması olarak farklı yüzey işlemlerinde ve türde seramik, mermer, laminat, doğal taş, PVC, cam, metal, granit vb. malzemeler kullanılmaktadır.

$\mathrm{Bu}$ tarz malzemelerin tercih edilmesinde kaydırmazlık gibi güvenlik unsurları yerine estetik, parlaklık, güzellik vb. özellikler ön plana çıkmakta ve tercih nedeni olmaktadır. Kaplama zeminlerde meydana gelebilecek kayma ve düşme vakalarını ve oluşabilecek hukuki sorunları önleyebilmek için önceden zemin malzemelerinin sslak ve kuru ortam kayma risk değerlerinin belirlenmesi gerekmektedir [10].

Çalışma kapsamında 7 farklı kamu kurumunda bulunan 5 farklı alandaki (Giriş, Koridor, Oda, Merdiven, Lavabo) zemin kaplamaları için kuru ve sslak ortam dinamik sürtünme katsayıları DCOF $(\mu)$ ölçülmüştür. Ölçüm yapılan kamu kurumları ve ölçüm alanları Tablo 1'de verilmiştir.

Tablo 1. Ölçüm yapılan kamu kurumları ve ölçüm alanları

\begin{tabular}{|l|c|c|}
\hline $\begin{array}{c}\text { Ölçüm Yapılan } \\
\text { Kurum Adı }\end{array}$ & $\begin{array}{c}\text { Ölçüm } \\
\text { Yapılan } \\
\text { Alanlar }\end{array}$ & $\begin{array}{c}\text { Ölçüm Yapılan } \\
\text { Alan } \\
\text { Zemin Özelliği }\end{array}$ \\
\hline K1 Okul & Giriş & Bej Mermer \\
K2 Kurum & Seramik \\
K3 Ana Okulu & Koridor & Serflor \\
K4 Özel Hastane & Oda & Laminant \\
K5 SGK & Merdiven & PVC \\
K6 Üniversite & Lavabo & Karo taş1 \\
K7 Özel Hastane & & Granit \\
& & Yapay Granit \\
\hline
\end{tabular}




\section{GMG 200 Sürtünme Katsayısı Ölçüm Test Cihazı}

Çalışma kapsamında ıslak ve kuru ortamlarda gerçekleştirilen ölçümler mobil taşınabilir özellikteki GMG 200 test cihazı kullanılarak yapılmıştır. Test cihazı DIN 51131:2014- 03, EN 13893 ile TS CEN/TS 16165 Ek - D standartlarına göre çalışmaktadır (Şekil 1).

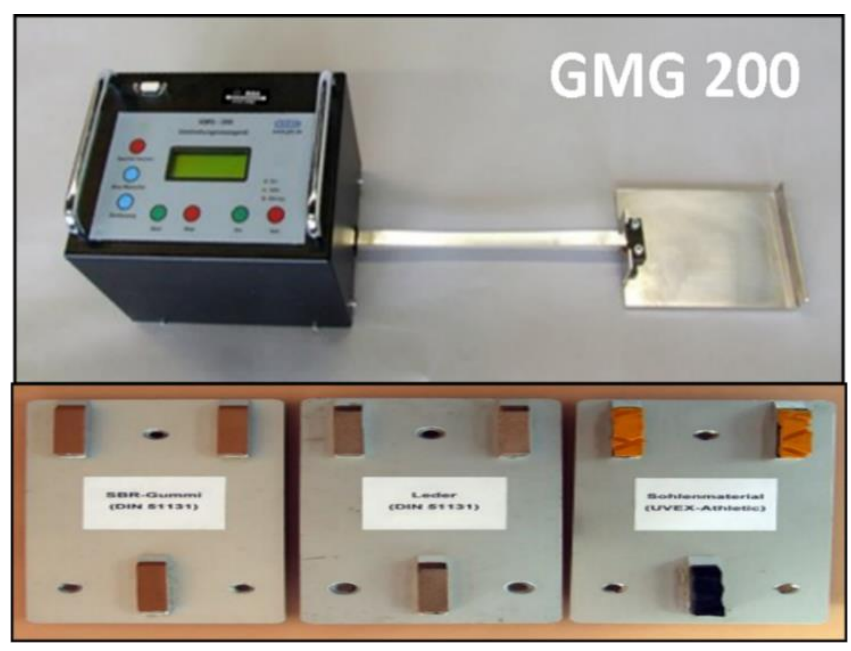

Şekil 1. GMG 200 test cihazı

Test cihazı altındaki kaydırıcı kızağa pabuç görevi gören farklı özellikteki malzemeler takılabilmektedir. $\mathrm{Bu}$ malzemeler ortamda yürüyüş için kullanılan ayakkabı, terlik vb. temsil etmektedir. Kaydırıcı kızak ve pabuçlar cihaza takıldıktan sonra ortam koşullarına uyum sağlaması için cihaz 30 dakika bekletilir. Daha sonra ölçüm yapılacak yerde beş adet ölçüm tekrarlanır. Önce kuru daha sonra ıslak ölçümler yapılır. Her ölçüm sonunda pabuçlar 320 numara zımpara ile plakaya baskı yapmadan eşit şekilde ileri ve geri hareket ettirilerek zımparalanır. Her ölçüm öncesi bu işlem tekrarlanmaktadır.

Ölçümler hem ıslak hem de kuru ortamda yapılmakta olup, test cihazı altında bulunan şerit çelik tel istenilen ölçü mesafesi kadar çekilir ve gerdirilir. Cihaz otomatik olarak ilerler ve ölçüm yapılır. Ölçümler beş defa tekrarlanır ve ilk iki ölçüm kalibrasyon amaçlı olduğundan atılır kalan üç ölçümün aritmetik ortalaması cihaz tarafından yapılarak ekranda gösterilir [11], [12].

\section{RapidMiner Programı}

RapidMiner, iş zekâsı, veri bilimi, makine öğrenmesi ve veri madenciliği gibi çok sayıda işlevin bünyesinde uyum içerisinde çalışmasını sağlayan, veriyi ön işlemeden ve diğer makine öğrenme süreçlerinden geçiren, raporlama ve görselleştirme yapabilen, uçtan uca çözümleme yapan bir araçtır. Yazılım 2001 yılında, YALE (Yet Another Learning Environment) olarak duyurulmuştur. Veri madenciliği, makine öğrenmesi vb. süreçlerin hemen hemen tamamını gerçekleştirebilecek kabiliyettedir. Java dilinde yazılmış bir programdır ve program içerisinde Java dili kullanarak kod yazma imkanı sunmaktadır. Ayrıca Python, Weka veya R vb. ortam ve diller ile entegre çalışabilmektedir [13].

\section{K-Ortalamalar Yöntemi}

K-Ortalamalar Yönteminde amaç, verileri belirli özelliklerine göre kümelere ayırarak gruplamaktır. $\mathrm{N}$ tane veriden oluşan bir veri grubunu $\mathrm{K}$ adet kümeye bölmekteki amaç bölümleme yolu ile elde edilen kümelerin, küme içerisinde birbirleriyle olan benzerliklerini maksimum; diğer kümelerle olan benzerliklerini minimum düzeye indirmektir.

Uygulama kolaylığı nedeniyle K-Ortalamalar Yöntemi yaygın olarak kullanılan bir yöntemdir. $\mathrm{K}$ verilerin kümeleneceği küme sayısını belirtmektedir. K-Ortalamalar Yönteminde itarasyonel şekilde devam eden tekrarlı bölümleme sayesinde verilerin bulunduğu kümeye olan uzaklıklar küçülür, böylelikle yöntem karesel hatanın en az olduğu $\mathrm{K}$ adet kümeyi bulmaya çalışır. İlk olarak her veri kümesinin merkez nokta veya ortalama değerini ifade eden rastgele $\mathrm{K}$ adet nesne belirlenir. Geriye kalan nesneler, ortalama küme değerlerine bakılarak bu değerlere olan uzaklıkları göz önüne alınarak kendilerine en yakın benzer kümelere alınır. Her bir küme için hesaplanan ortalama değerle birlikte kümeler için yeni merkezler belirlenir ve nesnelerin bu merkezlere olan uzaklıkları tekrar incelenir. $\mathrm{Bu}$ işlem veriler stabil hale gelip başka bir değişiklik olmayana kadar tekrarlı bir şekilde devam eder.

K- Ortalamalar Yöntemi temelde 4 aşamada gerçekleşir:

1. Kümeler için merkez tayin edilmesi

2. Merkez dişı kalan veriler için mesafelerin hesaplanması ve mesafelerine göre yeniden kümelendirilmesi

3. Kümelendirme işlemi sonrası yeni merkezlerin belirlenmesi (veya eski merkezlerin yeni merkeze kaydırılması)

4. Kararlılık sağlanana kadar (değişim olmama durumu) 2. ve 3. adımların tekrar edilmesi [14].

\section{Karar Ağacı Yöntemi}

Tahmin ve sınıflandırma işlemleri için sıkça kullanılan veri madenciliği yöntemlerinden biri de karar ağacı yöntemidir. Kolay yorumlanabilmesi ve anlaşılabilir olması açısından karar vericilere avantaj sağlamaktadır [15]. Karar Ağacı Yönteminde büyük miktardaki verileri küçük gruplara bölmek için basit karar verme adımları uygulanır. Gerçekleştirilen her başarılı bölme işlemi sonrasında veri grupları birbirlerine daha benzer olmaktadır [16]. Karar ağacı bir tane kök düğüm ve girdiler alan iç düğümlerden oluşmuş çok yönelimli bir ağaçtır [17]. Bu yöntemde veriler kökten yapraklara doğru bölünüp ilerlenerek kazanım yöntemine göre ağaç oluşturulur. İlk önce veriler ağacın kökünde toplanmıştır. Kazanım bilgi değerlerine bağlı olarak değişken seçimi gerçekleştirilir. Tekrarlı devam eden algoritmanın sonlanması için düğüm içerisinde mevcut tüm öğelerin aynı sinıfta yer alması gerekir. Kalan değerlerin yalnızca bir sınıftan olması ya da sinıflandırılacak herhangi bir değerin kalmaması durumunda tekrarlı devam eden algoritma sona erer ve ağaç tamamlanmış olur [18]. 


\section{Elde Edilen Verilerin Analizleri}

Çalışma kapsamında, K1'den K7'ye kadar 7 farklı kamu kurumunda, 5 farklı alanda (Giriş, koridor, oda, merdiven, lavabo) ve 2 farklı ortamda (kuru-1slak) DIN 51131:2014 03, EN 13893 ve TS CEN/TS 16165 Ek-D standartlarına göre çalışan mobil GMG 200 test cihazı kullanılarak dinamik sürtünme katsayısı DCOF $(\mu)$ değerleri ölçülmüştür (Şekil 2).

Her alanda 5 ölçüm gerçekleştirilmiş ve bu ölçüm değerlerinin ilk 2 tanesi kalibrasyon ve uyum nedeniyle değerlendirme dışı bırakılarak kalan 3 değerin aritmetik ortalaması alınmıştır. Kuru ve ıslak ortamda 7 farklı kurum, 5 farklı alanda gerçekleştirilen 3 ölçüm için toplamda 210 adet ölçüm değeri elde edilmiştir. Elde edilen aritmetik ortalama değerleri RapidMiner programında K-Ortalamalar Yöntemi kullanılarak gruplanmış, oluşan küme grupları sınır değerleri Karar Ağacı Yöntemi kullanılarak belirlenmiştir. Sonuçlar DIN 51131:2014 - 03, EN 13893 ve TS CEN/TS 16165 Ek - D Standartlarına göre Wuppertaler Tabelası kullanılarak değerlendirilmiştir.

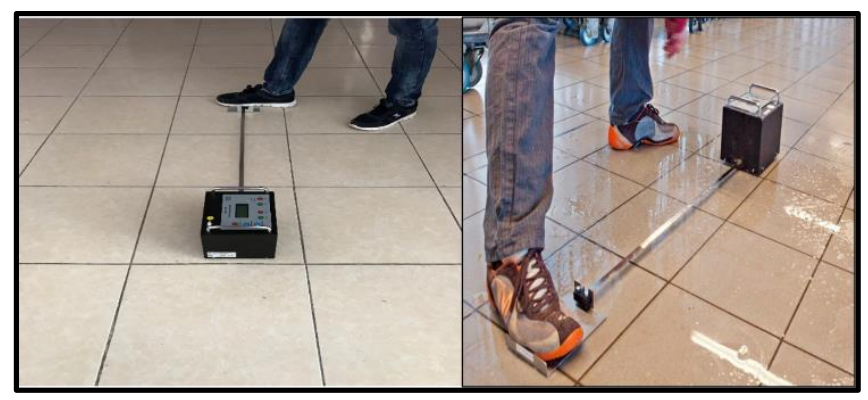

Şekil 2. GMG 200 Test cihazı ile yapılan kuru ve islak ortam ölçümleri

Dinamik sürtünme katsayılarının değerlendirilmesinde sıklıkla kullanılan Wuppertaller Tabelasında belirtilen sınır değerler için Güvensiz, Şartlı Güvenli, Güvenli ve Çok Güvenli gibi değerlendirmeler bulunmaktadır (Tablo 2).

Tablo 2. Wuppertaler Tabelası Sınır Değerleri [19], [20].

\begin{tabular}{|c|c|}
\hline \multicolumn{2}{|c|}{ Wuppertaler Tabelası } \\
\hline Sürtünme Katsayısı $(\mu)$ & Değerlendirme \\
\hline$\mu \geq 0.60$ & Çok Güvenli \\
\hline $0.45 \leq \mu<0.60$ & Güvenli \\
\hline $0.30 \leq \mu<0.45$ & Şartlı Güvenli \\
\hline$\mu<0.30$ & Güvensiz \\
\hline
\end{tabular}

Kuru ortam dinamik sürtünme katsayısı ölçüm değerlerinin aritmetik ortalamalarının değerlendirilmesi için Wupertaler Tabelasında değerlendirme derecesi olarak kullanılan Güvensiz, Şartlı Güvenli, Güvenli, Çok Güvenli durumları için $\mathrm{K}$ değeri 4 seçilmiştir. RapidMiner programında K-Ortalamalar Yöntemi kulllanılarak ölçüm değerlerinin aritmetik ortalamaları program tarafından cluster 0 , cluster 1 , cluster 2, cluster 3 olmak üzere 4 kümeye ayrılmıştır. Çalışmada cluster 0 , cluster 1 , cluster 2 , cluster 3 ifadeleri yerine bundan sonra sirasiyla Küme 0, Küme 1, Küme 2, Küme_3 ifadeleri kullanılacaktır. RapidMiner programında K-Ortalamalar Yöntemi ve Karar Ağacı Yöntemi
Kullanılarak program tarafından oluşturulan kümeler ve sınır değerleri Şekil 3'te görülmektir.

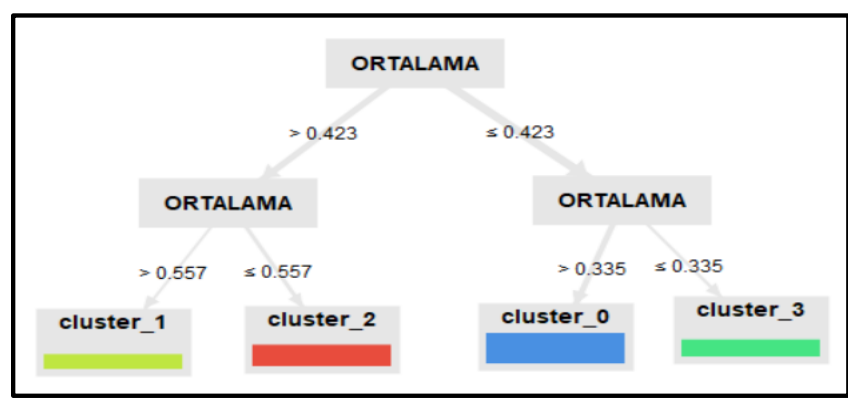

Şekil 3. Kuru Ortam için Karar Ağacı ve Gruplanmış Kümeler

RapidMiner programında K-Ortalamalar Yöntemine göre gruplanmış kuru ortam dinamik sürtünme katsayısı DCOF ( $\mu$ ) ölçüm değerleri aritmetik ortalamaları ile oluşan küme grupları için Karar Ağacı Yöntemi kullanılarak belirlenen küme sınır değerleri Tablo 3'te ve bu değerlerin Wuppertaler Tabelası ile karşılaştırılması Tablo 4'te verilmiştir.

Tablo 3. Kuru Ortam İçin Karar Ağacı Yöntemi ile belirlenen Sınır Değerleri

\begin{tabular}{|c|c|}
\hline \multicolumn{2}{|c|}{$\begin{array}{c}\text { Karar Ăgacı Yöntemi Kuru Ortam } \\
\text { Sinır Değerleri }\end{array}$} \\
\hline Sürtünme Katsayısı $(\mu)$ & Değerlendirme \\
\hline$\mu>0.557$ & Çok Güvenli \\
\hline $0.423<\mu \leq 0.557$ & Güvenli \\
\hline $0.335<\mu \leq 0.423$ & Şartlı Güvenli \\
\hline$\mu \leq 0.335$ & Güvensiz \\
\hline
\end{tabular}

RapidMiner programında K-Ortalamalar Yöntemi ve Karar Ağacı Yöntemi kullanılarak program tarafindan oluşturulan kümeler incelendiğinde 1 slak ortamda 7 farklı kurum, 5 farklı alanda gerçekleştirilen ölçümlerin aritmetik ortalamalarından oluşan 35 dinamik sürtünme katsayısı DCOF $(\mu)$ ölçüm değeri aritmetik ortalaması için:

Küme 0'da 13 dinamik sürtünme katsayısı DCOF ( $\mu$ ) ölçüm değeri aritmetik ortalaması kümelenmekte ve bu değerler Karar Ağacı Yöntemine göre $0.335<\mu \leq 0.423$ aralığında yer almaktadır (Şartlı Güvenli).

Küme 1'de 6 dinamik sürtünme katsayısı DCOF ( $\mu$ ) ölçüm değeri aritmetik ortalaması kümelenmekte ve bu değerler Karar Ağac1 Yöntemine göre $\mu>0.557$ olan değerler olmaktadır (Çok Güvenli).

Küme 2'de 9 dinamik sürtünme katsayısı DCOF ( $\mu$ ) ölçüm değeri aritmetik ortalaması kümelenmekte ve bu değerler Karar Ağacı Yöntemine göre $0.423<\mu \leq 0.56$ aralığında yer almaktadır (Güvenli).

Küme 3 'te 7 dinamik sürtünme katsayısı DCOF ( $\mu$ ) ölçüm değeri aritmetik ortalaması kümelenmekte ve bu değerler Karar Ağac1 Yöntemine göre $\mu \leq 0.335$ olan değerler olmaktadır (Güvensiz). 
Tablo 4. Kuru Ortam İçin K-Ortalamalar Yöntemi Kümeleri ve Karar Ağacı Yöntemi Sınır Değerlerinin Wuppertaler Tabelası Değerleri ile Kıyası

\begin{tabular}{|c|c|c|c|c|c|c|c|}
\hline $\begin{array}{c}\text { Kurum } \\
\text { Adı }\end{array}$ & $\begin{array}{c}\text { Ölçüm } \\
\text { Alanı }\end{array}$ & $\begin{array}{l}\text { Zemin } \\
\text { Özelliği }\end{array}$ & $\begin{array}{c}\text { DCOF } \\
\text { Ölçüm } \\
\text { Değerleri } \\
\text { Aritmetik } \\
\text { Ortalaması } \\
\end{array}$ & $\begin{array}{c}\text { K- } \\
\text { Ortalamalar } \\
\text { Yöntemi } \\
\text { Kümeler }\end{array}$ & $\begin{array}{l}\text { Karar Ağacı } \\
\text { Yöntemi } \\
\text { Küme Sınır } \\
\text { Değer Aralığı }\end{array}$ & $\begin{array}{c}\text { Karar Ağacı } \\
\text { Yöntemi } \\
\text { Değgerlendirme }\end{array}$ & $\begin{array}{l}\text { Wuppertaler } \\
\text { Tabelası } \\
\text { Değerlendirme }\end{array}$ \\
\hline \multirow{5}{*}{$\begin{array}{c}\text { K1 } \\
\text { Okul }\end{array}$} & Giriş & Bej Mermer & 0.37 & Küme 0 & $0.335<\mu \leq 0.423$ & Şartlı Güvenli & Şartlı Güvenli \\
\hline & Koridor & Seramik & 0.27 & Küme 3 & $\mu \leq 0.335$ & Güvensiz & Güvensiz \\
\hline & Oda & Serflor & 0.61 & Küme 1 & $\mu>0.557$ & Çok Güvenli & Çok Güvenli \\
\hline & Merdiven & Bej Mermer & 0.29 & Küme 3 & $\mu \leq 0.335$ & Güvensiz & Güvensiz \\
\hline & Lavabo & Seramik & 0.29 & Küme 3 & $\mu \leq 0.335$ & Güvensiz & Güvensiz \\
\hline \multirow{5}{*}{$\begin{array}{c}\text { K2 } \\
\text { Kurum }\end{array}$} & Giriş & Seramik & 0.33 & Küme 3 & $\mu \leq 0.335$ & Güvensiz & Şartlı Güvenli \\
\hline & Koridor & Seramik & 0.50 & Küme 2 & $0.423<\mu \leq 0.557$ & Güvenli & Güvenli \\
\hline & Oda & Laminant & 0.34 & Küme 0 & $0.335<\mu \leq 0.423$ & Şartlı Güvenli & Şartlı Güvenli \\
\hline & Merdiven & Seramik & 0.53 & Küme 2 & $0.423<\mu \leq 0.557$ & Güvenli & Güvenli \\
\hline & Lavabo & Seramik & 0.57 & Küme 1 & $\mu>0.557$ & Çok Güvenli & Güvenli \\
\hline \multirow{5}{*}{$\begin{array}{c}\text { K3 } \\
\text { Anaokulu }\end{array}$} & Giriş & Bej Mermer & 0.38 & Küme 0 & $0.335<\mu \leq 0.423$ & Şartlı Güvenli & Şartlı Güvenli \\
\hline & Koridor & Pvc & 0.60 & Küme 1 & $\mu>0.557$ & Çok Güvenli & Çok Güvenli \\
\hline & Oda & Laminant & 0.26 & Küme 3 & $\mu \leq 0.335$ & Güvensiz & Güvensiz \\
\hline & Merdiven & Bej Mermer & 0.36 & Küme 0 & $0.335<\mu \leq 0.423$ & Şartlı Güvenli & Şartlı Güvenli \\
\hline & Lavabo & Seramik & 0.40 & Küme 0 & $0.335<\mu \leq 0.423$ & Şartlı Güvenli & Şartlı Güvenli \\
\hline \multirow{5}{*}{$\begin{array}{c}\text { K4 } \\
\text { Özel } \\
\text { Hastane }\end{array}$} & Giriş & Seramik & 0.34 & Küme 0 & $0.335<\mu \leq 0.423$ & Şartlı Güvenli & Şartlı Güvenli \\
\hline & Koridor & Pvc & 0.64 & Küme 1 & $\mu>0.557$ & Çok Güvenli & Çok Güvenli \\
\hline & Oda & $\mathrm{Pvc}$ & 0.66 & Küme 1 & $\mu>0.557$ & Çok Güvenli & Çok Güvenli \\
\hline & Merdiven & Bej Mermer & 0.58 & Küme 1 & $\mu>0.557$ & Çok Güvenli & Güvenli \\
\hline & Lavabo & Seramik & 0.45 & Küme 2 & $0.423<\mu \leq 0.557$ & Güvenli & Güvenli \\
\hline \multirow{5}{*}{$\begin{array}{c}\text { K5 } \\
\text { SGK }\end{array}$} & Giriş & Bej Mermer & 0.46 & Küme 2 & $0.423<\mu \leq 0.557$ & Güvenli & Güvenli \\
\hline & Koridor & $\mathrm{Pvc}$ & 0.51 & Küme 2 & $0.423<\mu \leq 0.557$ & Güvenli & Güvenli \\
\hline & Oda & Laminant & 0.30 & Küme 3 & $\mu \leq 0.335$ & Güvensiz & Şartlı Güvenli \\
\hline & Merdiven & Bej Mermer & 0.40 & Küme 0 & $0.335<\mu \leq 0.423$ & Şartlı Güvenli & Şartlı Güvenli \\
\hline & Lavabo & Seramik & 0.38 & Küme 0 & $0.335<\mu \leq 0.423$ & Şartlı Güvenli & Şartlı Güvenli \\
\hline \multirow{5}{*}{$\begin{array}{c}\text { K6 } \\
\text { Üniversite }\end{array}$} & Giriş & Karo Taşı & 0.37 & Küme 0 & $0.335<\mu \leq 0.423$ & Şartlı Güvenli & Şartlı Güvenli \\
\hline & Koridor & Karo Taşı & 0.37 & Küme 0 & $0.335<\mu \leq 0.423$ & Şartlı Güvenli & Şartlı Güvenli \\
\hline & Oda & Laminant & 0.46 & Küme 2 & $0.423<\mu \leq 0.557$ & Güvenli & Güvenli \\
\hline & Merdiven & Bej Mermer & 0.54 & Küme 2 & $0.423<\mu \leq 0.557$ & Güvenli & Güvenli \\
\hline & Lavabo & Seramik & 0.34 & Küme 0 & $0.335<\mu \leq 0.423$ & Şartlı Güvenli & Şartlı Güvenli \\
\hline \multirow{5}{*}{$\begin{array}{c}\text { K7 } \\
\text { Özel } \\
\text { Hastane }\end{array}$} & Giriş & Yapay Granit & 0.36 & Küme 0 & $0.335<\mu \leq 0.423$ & Şartlı Güvenli & Şartlı Güvenli \\
\hline & Koridor & Yapay Granit & 0.31 & Küme 3 & $\mu \leq 0.335$ & Güvensiz & Şartlı Güvenli \\
\hline & Oda & Pvc & 0.50 & Küme 2 & $0.423<\mu \leq 0.557$ & Güvenli & Güvenli \\
\hline & Merdiven & Granit & 0.46 & Küme 2 & $0.423<\mu \leq 0.557$ & Güvenli & Güvenli \\
\hline & Lavabo & Seramik & 0.39 & Küme 0 & $0.335<\mu \leq 0.423$ & Şartlı Güvenli & Şartlı Güvenli \\
\hline
\end{tabular}


Tablo 4. İncelendiğinde:

Kuru ortam değerleri için Karar Ağacı Yöntemi sınır değerleri kullanılarak yapılan değerlendirmenin Wuppertaler Tabelası kullanılarak yapılan değerlendirme ile \% 85 oranında uyumlu olduğu;

Şartlı Güvenli ve Güvensiz değerlendirme sınır değerleri için Karar Ağacı Yöntemi sınır değerlerinin Wuppertaler Tabelası sınır değerlerine göre daha güvenli tarafta kaldığ (Karar Ağacı Yöntemine göre Güvensiz, Wuppertaler Tabelasına göre Şartlı Güvenli);

Güvenli ve Çok Güvenli değerlendirme sınır değerlerinde Karar Ağacı Yöntemi sınır değerleri güvenlik düzeyinin Wuppertaler Tabelasına kıyasla biraz daha düşük olduğu;

K1 okul binası koridor seramik kaplamasının, merdiven bej mermer kaplamasının, lavabo seramik kaplamasının hem Karar Ağacı Yöntemi değerleri hem de Wuppertaler Tabelasına göre kayma potansiyelinin yüksek (Güvensiz) olduğu;

K2 kurum giriş seramik kaplamasının Karar Ağacı Yöntemi değerine göre kayma potansiyelinin yüksek (Güvensiz), Wuppertaler Tabelasına göre sınır değerde (Şartlı Güvenli) olduğu;

K3 anaokulu oda laminant kaplamasının hem Karar Ağacı Yöntemi değerleri hem de Wuppertaler Tabelasına göre kayma potansiyelinin yüksek (Güvensiz) olduğu;

K5 SGK oda laminant kaplamasının Karar Ağacı Yöntemi değerine göre kayma potansiyelinin yüksek (Güvensiz), Wuppertaler Tabelasına göre sınır değerde (Şartlı Güvenli) olduğu;

K7 özel hastane koridor yapay granit kaplamasının Karar Ağacı Yöntemi değerine göre kayma potansiyelinin yüksek (Güvensiz), Wuppertaler Tabelasına göre sınır değerde (Şartlı Güvenli) olduğu; görülmektedir.

Islak ortam dinamik sürtünme katsayısı ölçüm değerlerinin aritmetik ortalamalarının değerlendirilmesi için Wupertaler Tabelasında değerlendirme derecesi olarak kullanılan Güvensiz, Şartlı Güvenli, Güvenli, Çok Güvenli durumları için $\mathrm{K}$ değeri 4 seçilmiştir. RapidMiner programında K-Ortalamalar Yöntemi kulllanılarak ölçüm değerlerinin aritmetik ortalamaları program tarafindan cluster 0 , cluster 1 , cluster 2, cluster 3 olmak üzere 4 kümeye ayrılmıştır.

K-Ortalamalar Yöntemi sonucu oluşturulan kümeler Karar Ağacı Yöntemi ile değerlendirildiğinde sınır değerleri belirlenen küme sayısı RapidMiner programında Karar Ağacı Yöntemi tarafından 3 olarak (cluster 0, cluster 1, cluster 2) belirlenmiş, program tarafından cluster 3 kümesi cluster 1'e dahil edilmiştir (Şekil 4).

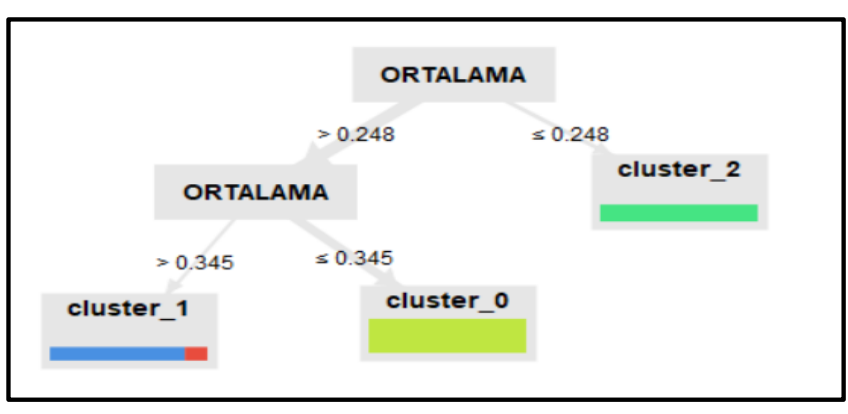

Şekil 4. Islak Ortam için Karar Ağacı ve Gruplanmış Kümeler

RapidMiner programında K-Ortalamalar Yöntemine göre gruplanmış ıslak ortam Dinamik sürtünme katsayısı DCOF ( $\mu$ ) ölçüm değerlerinin aritmetik ortalamaları ile oluşan küme grupları için Karar Ağacı Yöntemi kullanılarak belirlenen küme sınır değerleri Tablo 5'te ve bu değerlerin Wuppertaler Tabelası ile karşılaştırılması Tablo 6'da verilmiştir.

Tablo 5. Islak Ortam İçin Karar Ağacı Yöntemi ile belirlenen Sınır Değerleri

\begin{tabular}{|c|c|}
\hline \multicolumn{2}{|c|}{$\begin{array}{c}\text { Karar Ăgacı Yöntemi Islak Ortam } \\
\text { Sinır Değerleri }\end{array}$} \\
\hline Sürtünme Katsayısı $(\mu)$ & Değerlendirme \\
\hline$\mu>0.345$ & Güvenli \\
\hline $0.248<\mu \leq 0.345$ & Şartlı Güvenli \\
\hline$\mu \leq 0.248$ & Güvensiz \\
\hline
\end{tabular}

RapidMiner programında K-Ortalamalar Yöntemi ve Karar Ağacı Yöntemi kullanılarak program tarafından oluşturulan kümeler incelendiğinde 1slak ortamda 7 farklı kurum, 5 farklı alanda gerçekleştirilen ölçümlerin aritmetik ortalamalarından oluşan 35 dinamik sürtünme katsayısı DCOF $(\mu)$ ölçüm değeri aritmetik ortalaması için:

Küme 0'da 19 Dinamik sürtünme katsayısı DCOF $(\mu)$ ölçüm değeri aritmetik ortalaması kümelenmekte ve bu değerler Karar Ağacı Yöntemine göre $0.248<\mu \leq 0.345$ aralığında yer almaktadır (Şartlı Güvenli).

Küme 1'de 7 Dinamik sürtünme katsayısı DCOF ( $\mu$ ) ölçüm değeri aritmetik ortalaması kümelenmekte ve bu değerler Karar Ağacı Yöntemine göre $\mu>0.345$ olan değerler olmaktadır. Küme 1'de bulunan 7 değerden 1 tanesi program tarafından Küme 3'ten Küme 1'e dahil edilmiştir (Güvenli).

Küme 2'de 9 Dinamik sürtünme katsayısı DCOF ( $\mu$ ) ölçüm değeri aritmetik ortalaması kümelenmekte ve bu değerler Karar Ağacı Yöntemine göre $\mu \leq 0.248$ olan olmaktadır. (Güvensiz). 
Tablo 6. Islak Ortam İçin K-Ortalamalar Yöntemi Kümeleri ve Karar Ağacı Yöntemi Sınır Değerlerinin Wuppertaler Tabelası Değerleri ile Kıyası

\begin{tabular}{|c|c|c|c|c|c|c|c|}
\hline $\begin{array}{c}\text { Kurum } \\
\text { Adı }\end{array}$ & $\begin{array}{l}\text { Ölçüm } \\
\text { Alanı }\end{array}$ & $\begin{array}{l}\text { Zemin } \\
\text { Özelliği }\end{array}$ & $\begin{array}{c}\text { DCOF } \\
\text { Ölçüm } \\
\text { Değerleri } \\
\text { Aritmetik } \\
\text { Ortalaması }\end{array}$ & $\begin{array}{c}\text { K- } \\
\text { Ortalamalar } \\
\text { Yöntemi } \\
\text { Kümeler }\end{array}$ & $\begin{array}{l}\text { Karar Ağacı } \\
\text { Yöntemi } \\
\text { Küme Sınır } \\
\text { Değer Aralığı }\end{array}$ & $\begin{array}{c}\text { Karar Ăgacı } \\
\text { Yöntemi } \\
\text { Değgerlendirme }\end{array}$ & $\begin{array}{c}\text { Wuppertaler } \\
\text { Tabelası } \\
\text { Değerlendirme }\end{array}$ \\
\hline \multirow{5}{*}{$\begin{array}{c}\text { K1 } \\
\text { Okul }\end{array}$} & Giriş & Bej Mermer & 0.43 & Küme 1 & $\mu>0.345$ & Güvenli & Şartlı Güvenli \\
\hline & Koridor & Seramik & 0.21 & Küme 2 & $\mu \leq 0.248$ & Güvensiz & Güvensiz \\
\hline & Oda & Serflor & 0.33 & Küme 0 & $0.248<\mu \leq 0.345$ & Şartlı Güvenli & Şartlı Güvenli \\
\hline & Merdiven & Bej Mermer & 0.51 & Küme 3 & $\begin{array}{l}\text { Küme } 1 \\
\mu>0.248\end{array}$ & Güvenli & Güvenli \\
\hline & Lavabo & Seramik & 0.22 & Küme 2 & $\mu \leq 0.248$ & Güvensiz & Güvensiz \\
\hline \multirow{5}{*}{$\underset{\text { Kurum }}{\text { K2 }}$} & Giriş & Seramik & 0.23 & Küme 2 & $\mu \leq 0.248$ & Güvensiz & Güvensiz \\
\hline & Koridor & Seramik & 0.22 & Küme 2 & $\mu \leq 0.248$ & Güvensiz & Güvensiz \\
\hline & Oda & Laminant & 0.32 & Küme 0 & $0.248<\mu \leq 0.345$ & Şartlı Güvenli & Şartlı Güvenli \\
\hline & Merdiven & Seramik & 0.31 & Küme 0 & $0.248<\mu \leq 0.35$ & Şartlı Güvenli & Şartlı Güvenli \\
\hline & Lavabo & Seramik & 0.32 & Küme 0 & $0.248<\mu \leq 0.35$ & Şartlı Güvenli & Şartlı Güvenli \\
\hline \multirow{5}{*}{$\begin{array}{c}\text { K3 } \\
\text { Anaokulu }\end{array}$} & Giriş & Bej Mermer & 0.34 & Küme 0 & $0.248<\mu \leq 0.345$ & Şartlı Güvenli & Şartlı Güvenli \\
\hline & Koridor & Pvc & 0.28 & Küme 0 & $0.248<\mu \leq 0.345$ & Şartlı Güvenli & Güvensiz \\
\hline & Oda & Laminant & 0.23 & Küme 2 & $\mu \leq 0.248$ & Güvensiz & Güvensiz \\
\hline & Merdiven & Bej Mermer & 0.27 & Küme 0 & $0.248<\mu \leq 0.345$ & Şartlı Güvenli & Güvensiz \\
\hline & Lavabo & Seramik & 0.26 & Küme 0 & $0.248<\mu \leq 0.345$ & Şartlı Güvenli & Güvensiz \\
\hline \multirow{5}{*}{$\begin{array}{c}\text { K4 } \\
\text { Özel } \\
\text { Hastane }\end{array}$} & Giriş & Seramik & 0.18 & Küme 2 & $\mu \leq 0.248$ & Güvensiz & Güvensiz \\
\hline & Koridor & Pvc & 0.39 & Küme 1 & $\mu>0.345$ & Güvenli & Şartlı Güvenli \\
\hline & Oda & Pvc & 0.34 & Küme 0 & $0.248<\mu \leq 0.345$ & Şartlı Güvenli & Şartlı Güvenli \\
\hline & Merdiven & Bej Mermer & 0.17 & Küme 2 & $\mu \leq 0.248$ & Güvensiz & Güvensiz \\
\hline & Lavabo & Seramik & 0.19 & Küme 2 & $\mu \leq 0.248$ & Güvensiz & Güvensiz \\
\hline \multirow{5}{*}{$\begin{array}{c}\text { K5 } \\
\text { SGK }\end{array}$} & Giriş & Bej Mermer & 0.42 & Küme 1 & $\mu>0.345$ & Güvenli & Şartlı Güvenli \\
\hline & Koridor & Pvc & 0.32 & Küme 0 & $0.248<\mu \leq 0.345$ & Şartlı Güvenli & Şartlı Güvenli \\
\hline & Oda & Laminant & 0.22 & Küme 2 & $\mu \leq 0.248$ & Güvensiz & Güvensiz \\
\hline & Merdiven & Bej Mermer & 0.35 & Küme 1 & $\mu>0.345$ & Güvenli & Şartlı Güvenli \\
\hline & Lavabo & Seramik & 0.30 & Küme 0 & $0.248<\mu \leq 0.35$ & Şartlı Güvenli & Şartlı Güvenli \\
\hline \multirow{5}{*}{$\begin{array}{c}\text { K6 } \\
\text { Üniversite }\end{array}$} & Giriş & Karo Taşı & 0.36 & Küme 1 & $\mu>0.345$ & Güvenli & Şartlı Güvenli \\
\hline & Koridor & Karo Taşı & 0.34 & Küme 0 & $0.248<\mu \leq 0.345$ & Şartlı Güvenli & Şartlı Güvenli \\
\hline & Oda & Laminant & 0.31 & Küme 0 & $0.248<\mu \leq 0.345$ & Şartlı Güvenli & Şartlı Güvenli \\
\hline & Merdiven & Bej Mermer & 0.29 & Küme 0 & $0.248<\mu \leq 0.345$ & Şartlı Güvenli & Güvensiz \\
\hline & Lavabo & Seramik & 0.27 & Küme 0 & $0.248<\mu \leq 0.345$ & Şartlı Güvenli & Güvensiz \\
\hline \multirow{5}{*}{$\begin{array}{c}\text { K7 } \\
\text { Özel } \\
\text { Hastane }\end{array}$} & Giriş & Yapay Granit & 0.28 & Küme 0 & $0.248<\mu \leq 0.345$ & Şartlı Güvenli & Güvensiz \\
\hline & Koridor & Yapay Granit & 0.27 & Küme 0 & $0.248<\mu \leq 0.345$ & Şartlı Güvenli & Güvensiz \\
\hline & Oda & Pvc & 0.41 & Küme 1 & $\mu>0.345$ & Güvenli & Şartlı Güvenli \\
\hline & Merdiven & Granit & 0.32 & Küme 0 & $0.248<\mu \leq 0.345$ & Şartlı Güvenli & Şartlı Güvenli \\
\hline & Lavabo & Seramik & 0.29 & Küme 0 & $0.248<\mu \leq 0.345$ & Şartlı Güvenli & Güvensiz \\
\hline
\end{tabular}


Tablo 6. incelendiğinde:

Islak ortam değerleri için, Karar Ağacı Yöntemi sınır değerleri kullanılarak yapılan değerlendirmenin Wuppertaler Tabelası kullanılarak yapılan değerlendirme ile \% 60 oranında uyumlu olduğu;

K1 okul binası koridor seramik kaplamasının ve lavabo seramik kaplamasının hem Karar Ağacı Yöntemi değerleri hem de Wuppertaler Tabelasına göre kayma potansiyelinin yüksek (Güvensiz) olduğu;

K2 kurum giriş seramik kaplamasının ve koridor seramik kaplamasının hem Karar Ağacı Yöntemi değerleri hem de Wuppertaler Tabelasına göre kayma potansiyelinin yüksek (Güvensiz) olduğu;

K3 anaokulu oda laminant kaplamasının, hem Karar Ağacı Yöntemi değerleri hem de Wuppertaler Tabelasına göre kayma potansiyelinin yüksek (Güvensiz) olduğu;

K3 anaokulu koridor PVC kaplamasının, merdiven bej mermer kaplamasının, lavabo seramik kaplamasının Karar Ağacı Yöntemi değerine göre sınır değerde (Şartlı Güvenli), Wuppertaler Tabelasına göre kayma potansiyelinin yüksek (Güvensiz) olduğu;

K4 özel hastane giriş seramik kaplamasının, merdiven bej mermer kaplamasının, lavabo seramik kaplamasının hem Karar Ağacı Yöntemi değerleri hem de Wuppertaler Tabelasına göre kayma potansiyelinin yüksek (Güvensiz) olduğu;

K5 SGK oda laminant kaplamasının hem Karar Ağacı Yöntemi değerleri hem de Wuppertaler Tabelasına göre kayma potansiyelinin yüksek (Güvensiz) olduğu;

K6 üniversite merdiven bej mermer kaplamasının ve lavabo seramik kaplamasının Karar Ağacı Yöntemi değerine göre sınır değerde (Şartlı Güvenli), Wuppertaler Tabelasına göre kayma potansiyelinin yüksek (Güvensiz) olduğu;

K7 özel hastane giriş yapay granit kaplamasının, koridor yapay granit kaplamasının, lavabo seramik kaplamasının Karar Ăgacı Yöntemi değerine göre sınır değerde (Şartlı Güvenli), Wuppertaler Tabelasına göre kayma potansiyelinin yüksek (Güvensiz) olduğu görülmektedir.

Tablo 4. ve Tablo 6. beraber incelendiğinde K1 okul giriş bej mermer kaplaması ve merdiven bej mermer kaplaması için yapılan ölçümlerde kuru ortam dinamik sürtünme katsayısı değerlerinin aritmetik ortalamasının 1slak ortam dinamik sürtünme katsayısı değerlerinin aritmetik ortalamasından beklenilenin aksine daha düşük ölçüldüğü görülmektedir. Çalışma alanında gerçekleştirilen ölçümlerde görülen bu fark, zemin kaplaması yüzeyinde oluşan kum ve toz parçacıklarının kuru ortamda kaymayı arttırıcı etki ile dinamik sürtünme katsayısını düşürmesi, sslak ortamda ise meydana gelen vakum etkisinin kaymayı azaltıcı etki ile dinamik sürtünme katsayısını arttırması ile gerçekleştiği şeklinde açıklanabilir.

Çalışma yapılan kamu kurumlarının genelinde, zemin kaplaması olarak kullanılan seramik malzemelerin kayma risk potansiyelinin yüksek olduğu görülmektedir. Kayma risk potansiyeli yönünden en riskli kurum incelenen 5 mahalden 4 ün de kayma riski bulunan anaokulu iken en güvenli kurum incelenen 5 mahalden 1 'inde kayma riski bulunan K5 SGK olarak belirlenmiştir.

\section{Sonuç:}

7 farklı kamu kurumu ve 5 farklı alanda islak ve kuru ortamlarda gerçekleştirilen ölçümler sonrası elde edilen dinamik sürtünme katsayısı ölçüm değerlerinin aritmetik ortalamaları RapidMiner programında K-Ortalamalar ve Karar Ağacı yöntemleri beraber kullanılarak kümelenmiştir. Küme sınır değerleri ve bu değerlere karşılık gelen (Güvensiz, Şartlı Güvenli, Güvenli, Çok Güvenli) aralıklar,

Kuru ortam için:

- $\quad \mu>0.557$ Çok Güvenli,

- $0.423<\mu \leq 0.557$ Güvenli,

- $0.335<\mu \leq 0.423$ Şartlı Güvenli,

- $\mu \leq 0.335$ Güvensiz,

Islak Ortam İçin:

- $\quad \mu>0.345$ Güvenli,

- $0.248<\mu \leq 0.345$ Şartlı Güvenli,

- $\mu \leq 0.248$ Güvensiz,

olarak belirlenmiştir.

Yapılan çalışmada kuru ortam değerleri için Karar Ağacı Yöntemi sınır değerleri kullanılarak yapılan değerlendirmenin Wuppertaler Tabelası kullanılarak yapılan değerlendirme ile \% 85 oranında uyumlu olduğu belirlenmiştir. Şartlı Güvenli ve Güvensiz değerlendirme sınır değerleri için Karar Ağacı Yöntemi sınır değerlerinin Wuppertaler Tabelası sınır değerlerine göre daha güvenli tarafta kaldığı (Karar Ağacı Yöntemine göre Güvensiz, Wuppertaler Tabelasına göre Şartlı Güvenli) ve Güvenli ve Çok Güvenli değerlendirme sınır değerlerinde Karar Ağacı Yöntemi sınır değerleri güvenlik düzeyinin Wuppertaler Tabelasına kıyasla biraz daha düşük olduğu (Karar Ağacı Yöntemine göre Güvenli, Wuppertaler Tabelasına göre Çok Güvenli) görülmüştür.

Yine aynı şekilde Islak ortam değerleri için, Karar Ağacı Yöntemi sınır değerleri kullanılarak yapılan değerlendirmenin Wuppertaler Tabelası kullanılarak yapılan değerlendirme ile \% 60 oranında uyumlu olduğu belirlenmiştir.

Çalışma neticesinde RapidMiner, Weka, Knime, Orrange vb. veri madenciliği programlarının İnşaat Mühendisliği alanında yapılan teknik ve akademik çalışmalar sırasında 
elde edilen verilerin gruplanması ve değerlendirilmesinde kullanılabileceği değerlendirilmektedir.

İnceleme yapılan kamu kurumlarına ait zemin kaplamalarının çoğunluğunun kayma güvenliği konusunda sınır değerde olduğu tespit edilmiştir. Kamu kurumları içerisinde kayma güvenliği konusunda en güvenli kurum K5 SGK olurken, en güvensiz kurum K3 Anaokulu 'dur. Yapılan incelemelerde kamu kurumlarında zemin kaplaması olarak kullanılan seramik malzemelerin dinamik sürtünme katsayısı DCOF $(\mu)$ değerlerinin düşük olduğu tespit edilmiştir. $\mathrm{Bu}$ nedenle kuru ve sslak ortamlarda kullanılan mevcut zemin kaplamaları üzerinde ya gerekli güvenlik önlemlerinin alınması ya da bu zemin kaplamalarının dinamik sürtünme katsayısı DCOF $(\mu)$ değerleri yüksek zemin kaplamaları ile değiştirilmesi önerilmektedir.

Sonuç olarak, ülkemizde son dönemde çıkan yasa, yönetmelik ve standartlar çerçevesinde tüm kamu kurum ve özel sektörlerde özellikle sslak ortamlarda kullanılan zemin kaplamalarının kaymaz özellikte olması istenmektedir. Bu nedenler mevcut ve yeni yapılacak alanlarda zemin kaplamalarının kuru ve ıslak ortamda kayma potansiyellerinin belirlenmesi ve güvenlik sınıflamalarının yapılması son derece önemlidir. Özellikle büyük çalışma alanlarında zemin kaplamalarının kuru ve ıslak ortamda kayma risklerinin belirlenerek kaymazlık risk haritasının çıkarılması ve güvenlik sınıflamasının yapılarak hem insanların güvenli hareket edebilmeleri hem de İş Sağlığı ve Güvenliği açısından son derece önemlidir.

\section{Kaynaklar}

[1] Ulusal Zemin Güvenliği Enstitüsü, URL: https://uz ge.org/hakkimizda (Erişim Kasım. 03, 2021)

[2] Social Security Institution-SGK, "Worker Health and Business Safety Report”, Turkey, 2017.

[3] G. Coşkun, "Karbonat Kökenli Bazı Doğal Taşlarda Yüzey İşleme Tekniklerinin ve Pürüzlülüğün Kayma Direncine Etkileri'", Fen Bilim. Enstitüsü Doktora Tezi 293s, 2013.

[4] G. Çoşkun, "Slip Risk Evaluation of Surface Coating Natural Stone Used in Health Institution," 1.Uluslararasi Iş Güvenliği Ve Çalişan Sağliği Kongresi , 2016

[5 ] Radikal, URL: http://www.radikal.com.tr/ turkiye/ ali sveris_merkezine_kaygan_zemin_cezas11016575/ (erişim Eyl. 10, 2021).

[6] Cumhuriyet, URL: https://www. cumhuriyet.com.tr/ haber/ izmirde- islak-zeminde- dusen-saglikci- tazminatdavasini-kazandi- 698730 (Erişim Eylül. 10, 2021).

[7] Hürriyet, URL: https://www.hurriyet.com.tr/gundem/a vmde- islak zemin- yuzunden- dustu- tazminat- kazandiemsal- karar- cikti-41771404 (Erişim Eylül. 10, 2021).
[8] G. Coşkun ve G. Sarışık, "Analysis of slip safety risk by portable floor slipperiness tester in state institutions", J. Build. Eng., c. 27, s. 100953, 2020.

[9] G. Çoşkun ve G. Sariişik, "Kamu Kurumlarinda Kullanilan Zemin Kaplamalarinin Yerinde Ve Laboratuvar Ortaminda Kayma Risk Skalasinin Belirlenmesi,"9.Ulusla arasi Iş Sağligi Ve Güvenliği Kongresi 2018.

[10] G. Coşkun ve G. Sarışık, "Determınatıon And Evaluatıon Of Slıp Risk Of Floor Coverıngs Used In Publıc Institutions", Determination And Evaluation Of Slip Risk Of Floor Coverings Used In Public Institutions, Adana, Turkey, Nov. 2017, c. 890, ss. 352-363.

[11] G. Coşkun ve G. Sarışık, "Eğitim Kurumlarında Kullanılan Zemin Kaplamalarının Kayma Risklerinin (Pot ansiyellerinin) Belirlenmesi ve Güvenlik Sınıflamasının Yapılması", program adı: 9. Uluslararası iş sağlığı ve güvenliği kongresi, İstanbul Türkiye, May. 2018.

[12] G. Coskun And G. Sarisik, "Taşinabilir Ve Laboratuar Zemin Kaymazlik Test Cihazi Ile Kayma Güvenliği Risk Analizi," Internatıonal Agean Symposıum On Innovatıve Interdıscıplınary Scıentıfıc Researches, 2019

[13] Ş.E. Şeker ve D. Erdoğan RapidMiner ile Veri Madenciliği. Antalya: Bilgisayar Kavramları Yayınları, 2016.

[14] Vikipedi, URL: https://tr.wikipedia.org/w/index.php? title=K- means_k\%C3\%BCmeleme\&oldid=20796946 Erişim Eylül. 11, 2021)

[15] C. F. Chien, L. F. Chen, "Data Mining to Improve Personnel Selection and Enhance Human Capital: A Case Study in High-Technology Industry," Expert Systems with Applications, vol. 34, p. 280-290, 2008.

[16] J. Sun and H. Li, "Data Mining Method for listed companies' financial distress prediction," KnowledgeBased Systems, vol. 21, no. 1, pp. 1-5, 2008.

[17] O., Maimon, L. Rokach, "Classification Trees". Data Mining and Knowledge Discovery Handbook, Editör: O., Maimon, L. Rokach, Springer, New York, A.B.D., 149-175, 2010 .

[18] G. O. Temel, H. Çamdeviren, Z. Akkuş, "Sınıflama Ağaçları Yardımıyla Restless Legs Syndrome (RLS) Hastalarına Tanı Koyma", 2005.

[19] R. Skiba, "Taschenbuch Arbeitssicherheit", 9. Auf lage, Berlin, Erich Schmidt Verlag 1997.

[20] G. Lehder / R. Skiba, "Taschenbuch Arbeitssiche rheit", 11. Auflage, Erich Schmidt Verlag 2011. 